\title{
Arabic Translation of the Weight Self-Stigma Questionnaire: Instrument Validation Study of Factor Structure and Reliability
}

Nasser F BinDhim ${ }^{1,2}$, PhD; Nora A Althumiri ${ }^{1}$, MSc; Mada H Basyouni ${ }^{1}$, MPhil; Omar T Sims ${ }^{3}$, PhD; Noara Alhusseini ${ }^{2}$, $\mathrm{PhD}$; Saleh A Alqahtani ${ }^{4,5}, \mathrm{MD}$

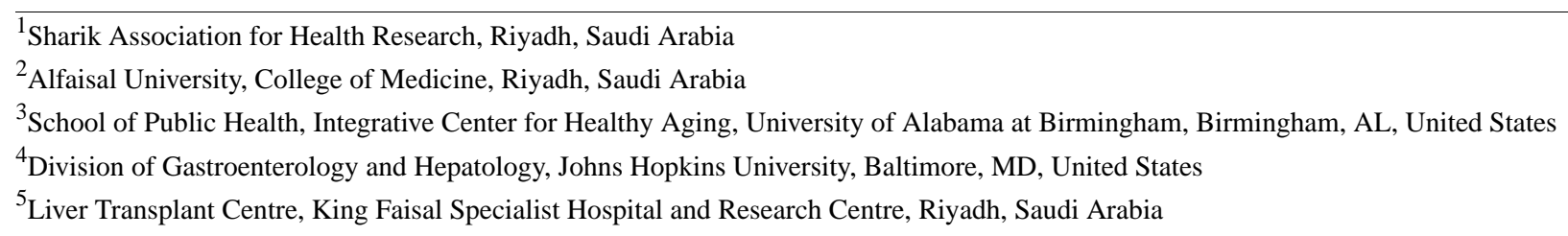

Corresponding Author:

Nasser F BinDhim, PhD

Sharik Association for Health Research

4 anas ibn malik Rd

Riyadh, 11778

Saudi Arabia

Phone: 966580033299

Email: nd@nasserdhim.com

\section{Abstract}

Background: While it is most often associated with its effects on physical health, obesity is also associated with serious self-stigmatization. The lack of a suitable, validated tool to measure weight-related self-stigma in Arabic countries may be partly responsible for the scarcity of literature about this problem.

Objective: This study investigated the reliability and validity of an Arabic version of the Weight Self-Stigma Questionnaire (WSSQ).

Methods: Data on the Arabic-translated version of the 12-item WSSQ were collected using two cross-sectional electronic questionnaires distributed among Saudi nationals through the Sharik Association for Health Research's database in June 2020. Internal consistency, test-retest reliability, and exploratory factor analysis of the Arabic WSSQ were assessed and compared with the original English version and other translations.

Results: For reliability analysis, 43 participants completed the Arabic WSSQ during two time periods. Internal consistency was $\alpha=.898$ for the overall survey, $\alpha=.819$ for the fear of enacted stigma subscale (factor 1 ), and $\alpha=.847$ for the self-devaluation subscale (factor 2). The test-retest reliability of the intraclass correlation coefficient was $\alpha=.982$. In the factor structure analysis, 295 participants completed the questionnaire. The Arabic WSSQ loading of the items was consistent with the original WSSQ, except for the loading of item 9, which was stronger in factor 2 than in factor 1 . The two factors accounted for the observed variances of $47.7 \%$ and $10.6 \%$.

Conclusions: The Arabic version of the WSSQ has good internal consistency and reliability, and the factorial structure is similar to that of the original WSSQ. The Arabic WSSQ is adaptable for clinicians seeking to assess weight-related self-stigma in Arabic-speaking people.

(JMIR Form Res 2020;4(11):e24169) doi: 10.2196/24169

\section{KEYWORDS}

overweight; stigma; weight self-stigma; Weight Self-Stigma Questionnaire; obesity; Saudi Arabia; questionnaire; validation; reliability; validity 


\section{Introduction}

Obesity is a global health problem with serious complications, including cardiovascular disease, diabetes, and hypertension. It is significantly correlated with cancer, stroke, asthma, and reduced fertility [1]. From 1992 to 2005, the prevalence of obesity in Saudi men aged 25 to 34 years increased from $10.1 \%$ to $27.1 \%$, while the prevalence in Saudi women within the same age range increased from $16.1 \%$ to $39.5 \%$ [2]. Approximately $25 \%$ of the Saudi Arabian population suffers from obesity, and around $35 \%$ of the total Saudi population is clinically overweight. Along with its impact on physical health, obesity is also associated with psychosocial complications, including stigmatization in health care, employment, education, and other settings.

Stigma enables various forms of discrimination that ultimately deny the individual or group full social acceptance, reduce the individual's opportunities [3], and fuel social inequalities [4], and it influences population health outcomes by worsening, undermining, or impeding a number of processes, including social relationships, stress, and psychological and behavioral responses [5,6]. Stigma and its effects are classified into two main types: public stigma and self-stigma. Public stigma has been described in terms of stereotypes, prejudice, and discrimination; self-stigma is the awareness of and agreement with public stigma stereotypes and attitudes and the application of those stereotypes to oneself, which undermine self-esteem and self-efficacy [7]. Thus, the availability of recent, high-quality data on health-related stigma or self-stigma is critical for improving interventions and programs to address them, yet such routine data are often lacking, sometimes due to a lack of validated tools for assessment [8].

To date, Arabic-speaking countries have no validated measure of weight self-stigma, constraining researchers' attempts to determine the prevalence of weight self-stigma and its contribution to adverse health and psychological effects. A reliable, validated Arabic tool would allow researchers to measure the impact of weight-stigma interventions on other health outcomes [9]. Although the Weight Self-Stigma Questionnaire (WSSQ) has wide global application, the translated version must be validated to make sure that it measures what it is intended to and produces results comparable to those of the original version. Translated versions of questionnaires are needed for researchers who intend to collect data among respondents who speak other languages, mainly to compare responses across populations of different languages and/or cultures [10]. In addition, researchers need to make sure that the translated questionnaires are assessing the equivalent construct with an equivalent metric [10].

Widespread clinical uptake of such a questionnaire can inform psychotherapeutic treatment options for overweight and obese patients experiencing psychological stressors from weight self-stigma, which impacts overall patient well-being. Obese patients who receive appropriate psychological treatment tend to lose weight and exhibit a reduction in obesity-related comorbidities [11]. Clinically, the WSSQ is used to diagnose and treat psychological issues associated with self-devaluation and fear of enacted stigma in obese and overweight patients, and such treatment can result in a range of positive outcomes, including decreased emotional overeating and increased health-promoting behaviors [12].

The WSSQ is a self-reported measure of weight-related self-stigma in overweight and obese persons. It has been translated and validated in German, French, Chinese, and Turkish, among other languages [13-16]. To date, a validated Arabic psychometric scale to evaluate weight-related self-stigma has not been adopted by clinicians. This paper reports the development and validation of an Arabic-translated version of the WSSQ. We also compared the internal consistency and test-retest reliability of the Arabic WSSQ with the original English WSSQ and other translations.

\section{Methods}

Analyses of test-retest reliability and exploratory factors were performed for the Arabic-translated version of the WSSQ using data collected via two cross-sectional electronic questionnaires distributed to Saudi nationals through the Sharik Association for Health Research's database in June 2020.

\section{WSSQ}

The WSSQ is a 12-item Likert-type measure of weight-related self-stigmatization (Table 1). It has two subscales that individually measure (1) weight-related self-devaluation and (2) fear of enacted stigma. The original version of the questionnaire had good psychometrics and a valid preliminary construct. Cronbach $\alpha$ coefficients were acceptable for the full scale $(\alpha=.878)$ and the two subscales $(\alpha=.869$ and $\alpha=.812)$ [9]. Analyses of principal components revealed a two-factor structure [9]. WSSQ items are rated on a scale of 1 (completely disagree) to 5 (completely agree). Sum scores are calculated for the full scale and each subscale. Items 1 to 6 constitute the self-devaluation subscale (factor 2), and items 7 to 12 constitute the fear of enacted stigma subscale (factor 1). There are no reverse-scored items. 
Table 1. Weight Self-Stigma Questionnaire items.

\begin{tabular}{ll}
\hline Item number & Item \\
\hline 1 & I'll always go back to being overweight. \\
2 & I caused my weight problems. \\
3 & I feel guilty because of my weight problems. \\
4 & I became overweight because I'm a weak person. \\
5 & I would never have any problems with weight if I were stronger. \\
6 & I don't have enough self-control to maintain a healthy weight. \\
7 & I feel insecure about others' opinions of me. \\
8 & People discriminate against me because I've had weight problems. \\
9 & It's difficult for people who haven't had weight problems to relate to me. \\
10 & Others will think I lack self-control because of my weight problems. \\
11 & People think that I am to blame for my weight problems. \\
12 & Others are ashamed to be around me because of my weight. \\
\hline
\end{tabular}

\section{Arabic Translation of the WSSQ}

Standard backward and forward translation was performed. One nutritionist and 2 research professionals independently conducted the forward translation, and 2 professional translators independently conducted the backward translation. A focus group composed of 8 participants was asked to answer and discuss the questionnaire, and their comments and understanding of each item's meaning were discussed in the first focus group. Another round of focus group discussions was conducted with a total of 2 focus groups, each with 8 participants. Based on these discussions, the language of the questionnaire items was edited and clarified further, and the final version produced received universal approval among the group members. The final translated items can be found in Multimedia Appendix 1.

\section{Study Stages}

\section{Test-Retest Reliability}

In June 2020, a group of randomly selected Arabic-speaking adults from the general Saudi population was invited to complete the questionnaire on an electronic form via the Sharik Association for Health Research's database. The population of this database project is composed of persons who are interested in participating in research projects. An increasing number of participants are registered, now more than 63,000 distributed across the 13 regions of Saudi Arabia [17]. Eligibility was determined automatically via the data collection system. The eligibility criteria were being age 18 years or older and using Arabic as the primary language. Individuals from the participant database who met the eligibility criteria were notified via SMS text message to complete the survey via unique survey links. Three reminders were sent to each potential participant within 1 week. If the participant did not respond, another participant with similar demographics was invited until the required sample size had been reached. The same participants completed the questionnaire again after 1 week. Participants were asked to complete all answers before submitting the questionnaire.

\section{Exploratory Factor Analysis}

In this stage, a group of randomly selected Arabic-speaking Saudi adults was invited to complete the questionnaire on an electronic form from the Sharik Association for Health Research's database [17]. Participants completed all answers before submitting the questionnaire. This phase used similar eligibility criteria and a similar recruitment process as was used in the test-retest stage.

\section{Sample Size}

Based on published literature, the recommended sample size for test-retest reliability is 20 to 40 participants [18,19]. The original study that established test-retest reliability of the WSSQ used 44 participants [9]. The recommended sample size for exploratory factor analysis is between 100 and 250 participants, while some studies recommend more than 300 participants to ensure rigorous psychometric validation [20]. The suggested sample size includes a minimum of 2 and a maximum of 20 participants per item. For this study, the recommended minimum sample size was 240 participants based on 20 participants per each of the 12 items on the WSSQ. Thus, the targeted sample size range was 240 to 300 participants.

\section{Statistical Analysis}

Similar to the original WSSQ validation process, internal consistency was assessed using the Cronbach $\alpha$ coefficient, and the test-retest reliability was assessed with the intraclass correlation coefficient. To assess the suitability for conducting an exploratory factor analysis, analyses of the correlation between the scale items were conducted using the Kaiser-Meyer-Olkin sample adequacy measure (nonsignificant results mean the data are suitable for factor analysis) and Bartlett test (significant results mean the data are suitable for factor analysis) [21-24]. To examine the factorial structure of the scales, an exploratory factor analysis using principal factor extraction was performed. The oblique rotation method was used to obtain clear factorial structures and enable comparison with the original study results; an item loading cutoff of greater than 0.15 was adopted, as in the original study, and factors with eigenvalues greater than 1.0 were retained [9]. There were no 
missing data, as all questions needed to be completed before submitting the questionnaire electronically. All statistical tests were performed using the IBM SPSS statistical package (version 20).

\section{Ethical Considerations}

The ethics committee of the Sharik Association for Health Research, Riyadh, Saudi Arabia, approved this research project according to national research ethics regulations. Participants gave consent electronically, which was recorded by the data collection system.

\section{Results}

\section{Participants' Characteristics}

Of the 43 participants in study stage 1 (for test-retest reliability), $48.8 \%$ (21/43) were male and the mean age was 34.4 years (range 18-66). Of the 295 participants in study stage 2 (for exploratory factor analysis), $48.5 \%$ (143/295) were male and the mean age was 33.6 years (range 18-70).

\section{Reliability}

Internal consistency measures for both the subscales and the overall scale were good. The internal consistency of the full Arabic WSSQ was $\alpha=.898$, and for the subscales-factor 1 and factor 2-internal consistency was $\alpha=.819$ and $\alpha=.847$, respectively. These values are similar to those observed in the original English version $(\alpha=.878$ overall, and $\alpha=.869$ and $\alpha=.812$ for the enacted stigma and self-devaluation subscales, respectively) [9]. In the analysis of test-retest reliability, the intraclass correlation coefficient was $\alpha=.982$.

\section{Factor Structure}

Correlation coefficients among the 12 items were all 0.3 or higher, except those for item 12, which were below 0.3 for some other items. The Kaiser-Meyer-Oklin value was 0.891, and values for Bartlett's test of sphericity reached statistical significance $(P<0.001)$.

An analysis of principal components revealed two components that explained $47.7 \%$ and $10.6 \%$ of the variance. The scree plot (Figure 1) revealed a break after the second component. Oblique rotation (Table 2) was performed to compare the results with the original scale, and identical variance explanations of $47.7 \%$ and $10.6 \%$ were found.

Test-retest reliability/stability with the intracorrelation coefficient was high. Exploratory factor analysis revealed that loading of the items for the Arabic WSSQ was consistent with that of the original English WSSQ, except for the loading of item 9 (Table 2), which loaded positively in both factors but more strongly in factor 2 than in factor 1 [9].

Figure 1. Scree plot for principal component analysis: Comparison of the 12 components of the Arabic WSSQ to evaluate statistical significance of components using a scree test to determine eigenvalues.

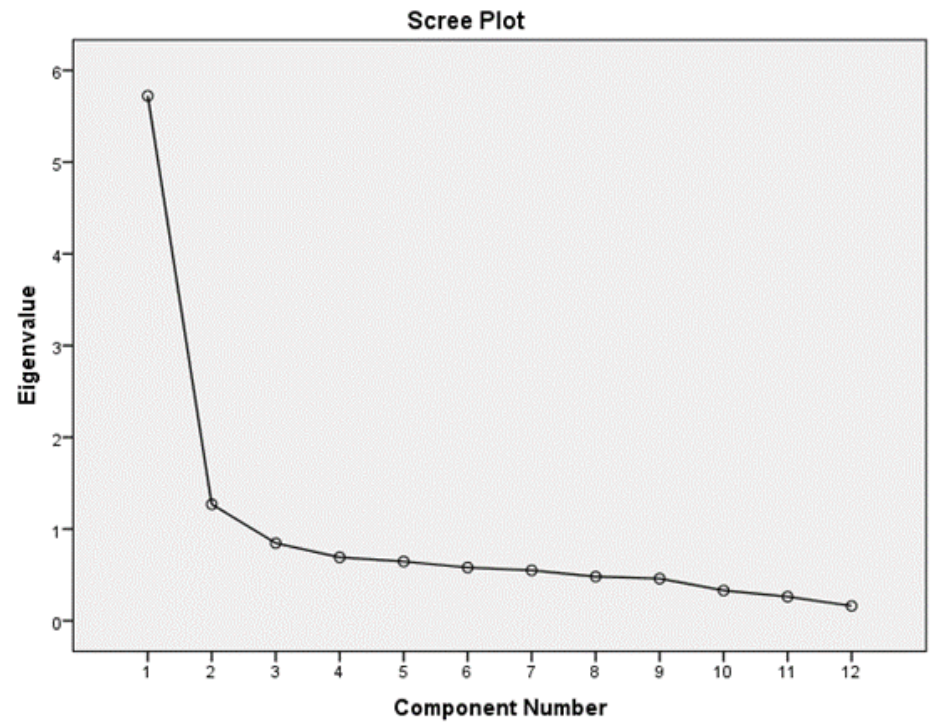


Table 2. Weight Self-Stigma Questionnaire items: item-scale correlations and factor loadings from principal components analysis with oblique rotation.

\begin{tabular}{|c|c|c|c|c|c|c|}
\hline \multirow[b]{2}{*}{ Item } & \multicolumn{3}{|l|}{ Arabic version } & \multicolumn{3}{|c|}{ English (original) version } \\
\hline & Item-scale correlation & Factor 1 & Factor 2 & Item-scale correlation & Factor 1 & Factor 2 \\
\hline 1 & 0.65 & 0.26 & 0.69 & 0.55 & Not reported & 0.55 \\
\hline 2 & 0.73 & 0.54 & 0.73 & 0.47 & Not reported & 0.66 \\
\hline 3 & 0.75 & 0.54 & 0.72 & 0.71 & Not reported & 0.69 \\
\hline 4 & 0.81 & 0.50 & 0.82 & 0.71 & Not reported & 0.81 \\
\hline 5 & 0.53 & 0.16 & 0.65 & 0.63 & Not reported & 0.69 \\
\hline 6 & 0.68 & 0.33 & 0.77 & 0.68 & Not reported & 0.79 \\
\hline 7 & 0.71 & 0.68 & 0.52 & 0.68 & 0.67 & Not reported \\
\hline 8 & 0.66 & 0.79 & 0.36 & 0.66 & 0.86 & Not reported \\
\hline 9 & 0.62 & 0.32 & 0.69 & 0.67 & 0.72 & Not reported \\
\hline 10 & 0.62 & 0.77 & 0.61 & 0.78 & 0.79 & Not reported \\
\hline 11 & 0.77 & 0.79 & 0.61 & 0.66 & 0.72 & Not reported \\
\hline 12 & 0.40 & 0.70 & 0.15 & 0.67 & 0.82 & Not reported \\
\hline
\end{tabular}

\section{Discussion}

\section{Principal Findings}

This study involved translating the WSSQ into Arabic and testing the reliability and validity of the Arabic-translated version. The Arabic WSSQ demonstrated good psychometric properties, which were congruent with the original English version of the WSSQ. The internal consistency of the Arabic WSSQ and its subscales (ie, fear of enacted stigma and self-devaluation) was good: $\alpha=.898, \alpha=.819$, and $\alpha=.847$, respectively. These values were consistent with the original English version of the WSSQ and its subscales: $\alpha=.878, \alpha=.869$, and $\alpha=.812$, respectively [9]. Test-retest reliability of the Arabic WSSQ was high at 0.982. Exploratory factor analysis showed that the loading of the majority of the questionnaire items (except item 9) was consistent with the original English version of the WSSQ.

We searched PubMed for any published research articles from Saudi Arabia about weight stigma in general and found no related articles. The lack of research conducted on weight-related stigma in Saudi Arabia may be the result of a lack of validated tools for assessing this topic. The validation of such a tool, as presented in this study, provides an initial means to fill that gap. More tools to measure weight-related stigma for different age groups and dimensions (eg, public weight stigma) are needed to expand this research field and generate more understanding about the impact of weight self-stigma on quality of life and psychological stress. Increased use of the Arabic WSSQ has the potential to close the gap between the well-known high prevalence of obesity and the scarcity of knowledge on the frequency and severity of weight self-stigma among Saudi adults. To enable the expansion of WSSQ utilization to
Arabic-speaking countries, we have provided the first Arabic translation of the WSSQ.

\section{Study Limitations and Strengths}

This study was not without notable limitations and strengths. The utility of the Arabic-WSSQ is not generalizable to children, as the study included only adults. A larger sample size is needed to assess the cross-cultural validity of this scale using confirmatory factorial analysis. Also, convergent validity was not assessed, and future studies are needed to assess correlations between the Arabic WSSQ and other scales that measure weight self-stigma.

However, the study had a high response rate among participants. The study's sample size was in line with published sample size recommendations for psychometric validation and was consistent with the sample size of the initial study that established the psychometric properties of the original English version of the WSSQ [9]. To our knowledge, this is the first Arabic translation of the WSSQ and the first demonstration of its psychometric properties among Arabic-speaking Saudi adults. The Arabic WSSQ not only allows researchers and clinicians to assess weight self-stigma among Arabic-speaking adults, but it provides researchers and clinicians with an empirical measure to assess the effectiveness of interventions to reduce weight self-stigma.

\section{Conclusion}

The Arabic WSSQ has good internal consistency and reliability. The factorial structure is similar to the original English WSSQ, which endorses its value for use in cross-cultural studies. The Arabic WSSQ appears to be a reliable measure for assessing weight-related self-stigma in Arabic-speaking people.

\section{Authors' Contributions}

All authors participated in the development and design of this study and in writing and reviewing the manuscript. All authors approved the final version of the manuscript. 


\section{Conflicts of Interest}

None declared.

\section{Multimedia Appendix 1}

Arabic translation and validation of the Weight Self-Stigma Questionnaire.

[DOCX File, 16 KB-Multimedia Appendix 1]

\section{References}

1. Kinlen D, Cody D, O'Shea D. Complications of obesity. QJM 2018 Jul 01;111(7):437-443. [doi: 10.1093/qjmed/hcx152] [Medline: 29025162]

2. Al-Quwaidhi AJ, Pearce MS, Critchley JA, Sobngwi E, O'Flaherty M. Trends and future projections of the prevalence of adult obesity in Saudi Arabia, 1992-2022. East Mediterr Health J 2014 Oct;20(10):589-595. [Medline: 25356689]

3. Goffman E. Stigma: Notes on the management of spoiled identity. New York: Simon \& Shuster; 1963.

4. Parker R, Aggleton P. HIV and AIDS-related stigma and discrimination: a conceptual framework and implications for action. Soc Sci Med 2003 Jul;57(1):13-24. [doi: 10.1016/s0277-9536(02)00304-0] [Medline: 12753813]

5. Stangl AL, Earnshaw VA, Logie CH, van Brakel W, C Simbayi L, Barré I, et al. The Health Stigma and Discrimination Framework: a global, crosscutting framework to inform research, intervention development, and policy on health-related stigmas. BMC Med 2019 Feb 15;17(1):31 [FREE Full text] [doi: 10.1186/s12916-019-1271-3] [Medline: $\underline{30764826}$ ]

6. Hatzenbuehler ML, Phelan JC, Link BG. Stigma as a fundamental cause of population health inequalities. Am J Public Health 2013 May;103(5):813-821 [FREE Full text] [doi: 10.2105/AJPH.2012.301069] [Medline: 23488505]

7. Corrigan PW, Larson JE, Rüsch N. Self-stigma and the ?why try? effect: impact on life goals and evidence-based practices. World Psychiatry 2009 Jun;8(2):75-81 [FREE Full text] [Medline: 19516923]

8. Stangl AL, Lloyd JK, Brady LM, Holland CE, Baral S. A systematic review of interventions to reduce HIV-related stigma and discrimination from 2002 to 2013: how far have we come? J Int AIDS Soc 2013 Nov 13;16(3 Suppl 2):18734 [FREE Full text] [Medline: 24242268]

9. Lillis J, Luoma JB, Levin ME, Hayes SC. Measuring weight self-stigma: the weight self-stigma questionnaire. Obesity (Silver Spring) 2010 May;18(5):971-976 [FREE Full text] [doi: 10.1038/oby.2009.353] [Medline: 19834462]

10. Tsang S, Royse CF, Terkawi AS. Guidelines for developing, translating, and validating a questionnaire in perioperative and pain medicine. Saudi J Anaesth 2017 May;11(Suppl 1):S80-S89 [FREE Full text] [doi: 10.4103/sja.SJA 203 17] [Medline: 28616007]

11. Faulconbridge LF, Wadden TA, Berkowitz RI, Pulcini ME, Treadwell T. Treatment of Comorbid Obesity and Major Depressive Disorder: A Prospective Pilot Study for their Combined Treatment. J Obes 2011;2011:870385 [FREE Full text] [doi: 10.1155/2011/870385] [Medline: 21773011]

12. Lillis J, Thomas JG, Levin ME, Wing RR. Self-stigma and weight loss: The impact of fear of being stigmatized. J Health Psychol 2020 Jun;25(7):922-930. [doi: 10.1177/1359105317739101] [Medline: 29105491]

13. Hain B, Langer L, Hünnemeyer K, Rudofsky G, Zech U, Wild B. Translation and validation of the German version of the weight self-stigma questionnaire (WSSQ). Obes Surg 2015 Apr;25(4):750-753. [doi: 10.1007/s11695-015-1598-6] [Medline: 25663147]

14. Lin KP, Lee ML. Validating a Chinese version of the Weight Self-stigma Questionnaire for use with obese adults. Int J Nurs Pract 2017 Aug;23(4). [doi: 10.1111/ijn.12537] [Medline: 28303628]

15. Maïano C, Aimé A, Lepage G, ASPQ Team, Morin AJS. Psychometric properties of the Weight Self-Stigma Questionnaire (WSSQ) among a sample of overweight/obese French-speaking adolescents. Eat Weight Disord 2019 Jun;24(3):575-583. [doi: 10.1007/s40519-017-0382-0] [Medline: 28390006]

16. Erdogan Z, Kurcer MK, Kurtuncu M, Catalcam S. Validity and reliability of the Turkish version of the weight Self-stigma questionnaire. J Pak Med Assoc 2018 Dec;68(12):1798-1803 [FREE Full text] [Medline: $\underline{30504938]}$

17. Sharik HRD. Sharik Association for Health Research. Accessed 2020 Sep 22. URL: https://sharikhealth.com/ [accessed 2020-09-22]

18. Walter SD, Eliasziw M, Donner A. Sample size and optimal designs for reliability studies. Stat Med 1998 Jan 15;17(1):101-110. [Medline: 9463853 ]

19. McMillan GP, Hanson TE. Sample size requirements for establishing clinical test-retest standards. Ear Hear 2014;35(2):283-286. [doi: 10.1097/01.aud.0000438377.15003.6b] [Medline: 24351613]

20. Arafat S, Chowdhury H, Qusar M, Hafez M. Cross Cultural Adaptation and Psychometric Validation of Research Instruments: a Methodological Review. J Behav Health 2016;5(3):129. [doi: 10.5455/jbh.20160615121755]

21. Tabachnick B, Fidell L, Ullman J. Using multivariate statistics. 7th ed. New York, USA: Pearson; 2019.

22. Kaiser HF. A second generation little jiffy. Psychometrika 1970 Dec;35(4):401-415. [doi: 10.1007/bf02291817]

23. Kaiser HF. An index of factorial simplicity. Psychometrika 1974 Mar;39(1):31-36. [doi: 10.1007/bf02291575]

24. Bartlett MS. A Note on the Multiplying Factors for Various $\chi$ Approximations. Journal of the Royal Statistical Society: Series B (Methodological) 2018 Dec 05;16(2):296-298. [doi: 10.1111/j.2517-6161.1954.tb00174.x] 


\section{Abbreviations}

WSSQ: Weight Self-Stigma Questionnaire

Edited by G Eysenbach; submitted 24.09.20; peer-reviewed by A Algarin; comments to author 16.10.20; revised version received 28.10.20; accepted 28.10.20; published 13.11.20

Please cite as:

BinDhim NF, Althumiri NA, Basyouni MH, Sims OT, Alhusseini N, Alqahtani SA

Arabic Translation of the Weight Self-Stigma Questionnaire: Instrument Validation Study of Factor Structure and Reliability JMIR Form Res 2020;4(11):e24169

URL: http://formative.jmir.org/2020/11/e24169/

doi: $10.2196 / 24169$

PMID: $\underline{33185558}$

CNasser F BinDhim, Nora A Althumiri, Mada H Basyouni, Omar T Sims, Noara Alhusseini, Saleh A Alqahtani. Originally published in JMIR Formative Research (http://formative.jmir.org), 13.11.2020. This is an open-access article distributed under the terms of the Creative Commons Attribution License (https://creativecommons.org/licenses/by/4.0/), which permits unrestricted use, distribution, and reproduction in any medium, provided the original work, first published in JMIR Formative Research, is properly cited. The complete bibliographic information, a link to the original publication on http://formative.jmir.org, as well as this copyright and license information must be included. 